\title{
PARENTAL INVOLVEMENT IN THE PHILIPPINES: A REVIEW OF LITERATURES
}

\author{
Melissa T. Bartolome ${ }^{1}$, Nordin Mamat ${ }^{2}$, Abdul Halim Masnan ${ }^{3}$ \\ bartolome.mt@pnu.edu.ph ${ }^{1}$,nordin@fppm.upsi.edu.my², abdul.halim@fppm.upsi.edu.my ${ }^{3}$ \\ Philippine Normal University, Philippines ${ }^{1}$, Universiti Pendidikan Sultan Idris
}

\begin{abstract}
Parental involvement refers to the amount of participation a parent has when it comes to the schooling of his/her children. Some schools foster healthy parental involvement, but sometimes parents has hesitations if they will involve themselves with their children's education. It has been advocated in Western countries. However, there is a body of literature that examines the significance of social and cultural influences and the effects of parents' involvement in and expectations of their children's development and learning. It is important for schools to recognize the existence of cultural variations in parent involvement because there are differences among parents with diverse background on when, why, and how they are involved in their children's education. Parenting is important in the Philippine society because family is viewed as a center to one's social world. But, social contexts in which Filipino families are embedded have changed rapidly over the past ten years (Ochoa \& Torre, n.d.). Children's learning is increasingly moving toward a broader vision of the $21^{\text {st }}$ century learning. As children's educations increasingly occur across a range of settings, parents are uniquely positioned to help ensure that these settings best support their children's specific learning needs. Thus, parental involvement researches remain misrepresentative of parents and the involvement that they have with their children's education (Jackson, 2010). The present study is using a qualitative research design that will investigate existing literatures on parental involvement in Early Childhood Education in terms of communicating from the school, volunteering and participating in school's activities, and learning at home. The study will rely on the analysis of documents in order to gain deeper understanding about parental involvement in the Philippines and propose a School-facilitated Parental Involvement (SPIn) Framework.
\end{abstract}

Keywords: Parental involvement, Philippines, School-facilitated Parental Involvement (SPIn) Framework

\section{INTRODUCTION}

Each child is vulnerable and can either be molded to be successful or made to fail in life. According to the Child and Youth Welfare Code of the Philippines, the child is one of the most important assets of the nation, the promotion and enhancement of the child's life and welfare is also anchored on the moral supervision and support given by his parents or guardians.

In order for a child to succeed, parents exert a lot of influence on their child's cognitive development in the early years and thus, the contact between home and school should be maintained, especially during the primary school years. Although family background appears to be a powerful determinant of parental involvement, most parents, if duly encouraged, are able to devote extra time and effort to assisting with their children's education, both in the home and school settings (Ho, 2009). Parent support and participation are well defined if the 
principal, teachers and parents go hand in hand in achieving the progress of the pupils and of the total school community (Evangelista, 2008).

Hoover-Dempsey \& Sandler describes parental involvement as a "rich vein" of continued parental influence in the lives of children as they develop through the elementary, middle and high school years. This implies that benefits of a strong home-school relationship don't end with children's achievement in early years of education but it persists through their adult life.

\section{Importance and Benefits of PI}

Many schools involve parents in school-based or school related activities. This constitutes parental involvement rather than parental engagement. According to Harris and Goodall (2007), parental involvement can encompass a whole range of activities with or within the school while parents view parental engagement as offering support to students while teachers tend to view it as a means to improved behavior.

Peters (2012) notes that "when schools have reputations for being successful, they generally have lots of engagement from parents" (p.46). Mwai Kimu (2012) concludes in his qualitative study on Parent Involvement in Public Primary Schools in Kenya that a society needs to increase its level of educational involvement and that starts with the support by the parents. He claims that parent-school linkages can be enhanced through the teacher/parent relationship because teachers are the main linkage of parents to the school, the teacher/parent relationship is critical to pupils' success and parent involvement.

Parents must be considered a constant and principle component of curriculum. (Nihat Şad \& Gürbüztürk, 2013). They add that success at school is guaranteed if school-based instruction is supported by parents' involvement at home. Involving parents in education has been reported to yield positive outcomes in many aspects including increased student attendance to and satisfaction with school, better academic achievement, motivation, school attachment, responsibility and confidence, better social adaptation and less discipline problems.

According to Sapungan, and Sapunga. (2014), if we involve the parents in educating their children, it is tantamount to saying that the school is proactive in implementing changes or development among the students. As parent's involvement is increased, teachers and school administrators also raise the chance to realize quality reform in education.

\section{Background of PI in the Philippines}

Family in the Philippines is perceived as an important part of the society. It has been shaped by the unique history, values, experiences, adaptations, and ways of being that characterize the 
Filipino people and their culture (Alampay, n.d.). Coupled with the long history of political and social strife, it would seem that Filipino parents face insurmountable challenges in raising their children (Blair, 2014).

According to Alampay (n.d), Filipino parents, in general, subscribe to authoritarian attitudes. Her study reveals that the foregoing cultural values of kapwa (helping others), hiya (shyness), and utang na loob (paying back) are among the interdependent themes that pervades the dynamics of Filipino parenting and parent- child relationships, which are characterized by respect for parental authority and obedience on the part of children, family cohesion, and meeting familial obligations. In her qualitative study on Parenting in the Philippines, findings show that Filipino parenting behaviors may shift in the years to come. The consequences of these emergent beliefs and behaviors for Filipino families and children's development will need to be fully examined before coming out with policies and framework for PI.

Although Filipino parents across all social class levels typically regard education as essential to their children's success and are willing to go to great lengths to help their children through school, retention is a major concern in Philippine school, as many students do not continue past their elementary grades (Blair, 2014). In his Comparative study of Filipino and U.S. Parents which uses Questionnaires from six different measures, it concludes that Filipino parents are engage in their children's education, and want them to succeed, yet the filial responsibilities engrained in their culture necessitates the needs of the family ahead of the needs of the individual child. In his study, it uses theories which envision the flow of family capital. It recommends future studies to attempt to examine more international samples, so as to explore cultural variations, and develop theories which can more readily account for both structural and cultural traits.

\section{Challenges of PI in the Philippines}

Due to the prevailing problem of the country which is poverty, a substantial number of students do not make the transition from elementary school to high school. The Department of Education (DepEd) data shows that for every 100 children who enter Grade 1, close to 15 do not make it into Grade 2, and roughly one-quarter or 24 percent have dropped out before Grade 4 (Luz, 2007). Meanwhile, on December 2013, the NSO Census of Population and Housing $(\mathrm{CPH})$ shows that out of the 71.5 million individuals who are 10 years old and above, 97.5 percent or 69.8 million are literate or could read and write (Selangan, 2015).

Under-investment in children is an identified problem in low-income developing countries (Monteflor et al., 2006) and because of the emerging economic problems of the country, both parents tend to work harder to earn money for them to meet the needs of the family (Evangelista, 2008 ; Ochoa \& Torre, n.d.).

In Monteflor (2006) study, parent interview and survey questionnaires in Cebu, Philippines is use to determine some over-weighting of parents on the academic achievement 
in their children. It reveals that parents' motivation is associated with preschool performance. It recommends that longitudinal studies on parent-child developmental strategies should be done to help learn more about early childhood education. These future researches can contribute to the later growth and development of children, income generation and occupational success, and offsets for observed vulnerabilities in disadvantaged environments.

However, the social contexts in which Filipino families are embedded have changed rapidly over the past ten years, possibly shaping in turn the ways in which parents and children think about and relate with each other (Ochoa \& Torre, n.d.). Nowadays, Filipino parents make enormous efforts to be involved in their children's schooling.

In the mixed method study of Evangelista (2008), it aims to find the relationship between academic involvement of grade one parents and their children's scholastic performance. It shows that academic involvement of parents is still visible to their children in terms of peers, school activities, and others. Because of this, parents are still involved in their child's learning with regards to other linkages he/she is in. It recommends that parents should participate and be involved in the development of their children's education especially during their fundamental years because this stage will be the foundations of children for them to accelerate in the next level of higher education and the school should consider informing parents on how much involvement they should give to improve their child's scholastic performance.

According to Nierva (2009), parent involvement in the Philippines is vague because there is still a need to improve parent involvement practices, especially those promoting the parents' active involvement in the child's learning at home and in school. Much of the practices of Filipino are brought about by history including the ways parents race their children. The Philippines are facing different problems that are cause and greatly affects families. Thus, our country, like other countries continually seeks for solutions to bridge the gap.

Ochoa and Torre (n.d.) recommend that "parenting programs may focus on facilitating communication between parent and child, training parents to communicate in a nonconfrontational manner, while also giving children an opportunity to express their thoughts and feelings" (p.49). In their study, it review published and unpublished researches on parenting, child-rearing and discipline conducted among Filipino families from 2004 to 2014 using document analysis. However, other researches have been more critical of the relevance of conceptions of parenting, as Filipino children may have different interpretations of parental control.

\section{PI Programs in the Philippines}

Like in other countries, in the Philippines, public or private schools have PTA or the ParentTeacher Association. It is guided by the Department of Education Memorandum No. 74 series of 1999. Every PTA provides mechanisms to ensure proper coordination with the members of the community, provides an avenue for discussing relevant concerns, and provides assistance and support to the school for the promotion of their common interest. Regular meetings are 
conducted with local government units, civic organizations and other stakeholders to foster unity and cooperation. As an organization operating in the school, the PTA adheres to all existing policies and implementing guidelines by the Department of Education. The PTA serves as support group and as a significant partner of the school whose relationship shall be defined by cooperative and open dialogue to promote the welfare of the students.

Another program held by Department of Education is the Brigada Eskwela. It is an annual program that brings together nationwide voluntary efforts of different stakeholders. Parents, teachers and other members of the community where a public school is located help one another for the school's maintenance and beautification every two weeks before the official start of classes. It started on 1998 upon the implementation on Republic Act 8525 or the AdoptA-School program (ASP). Its mission is to practice shared governance, bring the spirit of education to the community level, and utilize local resources to improve public schools. (www.deped.gov.ph)

\section{Home-School Connection in the Philippines}

The home as a learning support has been found as an important variable in child development (Arriero, 2006). Children perform better in school when they have opportunities to learn from their two primary contexts of development, namely, the home and school (Nierva, 2009). When parents, teachers and schools support one another and build a strong partnership, it will result to academic success.

According to Pineda (2008), mutual effort toward a shared goal implies shared responsibility of families and educators for supporting students as learners. In his study of the comparison of the parents' and school personnel's perceptions on the existing home-school collaboration program of a private school in Muntinlupa City, Philippines, it notes that forming connections among families and schools foster positive school and learning experiences for children and youth.

Meanwhile in the study of Arriero (2006), findings show that there are two main issues that arise from the amount of involvement the parents in their children's learning in the home -- the first is the type of communication the parents are able to sustain with the children and the second is the general influence of the parents in the home environment in terms of creating a learning environment. This implies that communication with parents tends to range either positive or praising of the children to negative disciplining for them to learn.

Although public or private schools have PTA in the Philippines, an organization which shows parents support and participation on school activities, parent practices are limited. Nierva (2009) study shows the relationship between parental involvement and family status variables of grade one parents in one of the private schools in Quezon City, Philippines using a survey questionnaire. It finds out that in order to facilitate a better home-school partnership, policies to guide practices regarding home-school collaboration at national, regional, division, 
and school levels must be developed. Thus, this study has a small number of participants and didn't use other instruments to validate the result of the survey.

\section{Models}

Brofenbrenner (1994) argues that in order to understand human development, one must consider the entire ecological system in which growth occurs. He further notes that this system is composed of five socially organized subsystems that help support and guide human growth. They range from microsystem, which refers to the relationship between a developing person and the immediate environment, such as school and family, to the macrosystem, which refers to institutional patterns of culture, such as the economy, customs, and bodies of knowledge.

Parents, teachers and school should be working hand in hand in preparing children spiritually, socially, emotionally, physically and intellectually. According to the works of Epstein, parents and schools recognize their shared interests in and responsibilities for children, and they work together to create better programs and opportunities for students. She explains this connection through her theory of overlapping spheres of influence which expresses that the external model of overlapping spheres of influence recognizes that the three major contexts in which students learn and grow - the family, the school, and the community - may be drawn together or pushed apart.

In the theory of overlapping spheres, there are some practices that schools, families, and communities conduct separately and some that they conduct jointly to influence children's learning and development. The internal model of the interaction of the three spheres of influence shows where and how complex and essential interpersonal relations and patterns of influence occur between individuals at home, at school, and in the community. These social relationships may be enacted and studied at an institutional level and at an individual level. Connections between educators or parents and community groups, agencies, and services can also be represented and studied within the model.

From this theory of overlapping spheres of influence comes a framework of six major types of involvement which evolves from many years of continuous studies. This framework has been a great help for educators around the world in developing home-school partnership programs and for researchers as well in finding ways on how to improve parenting involvement practices. Epstein typology of PI comprises Parenting. Assist families with parenting skills, family support, understanding child and adolescent development, and setting home conditions to support learning at each age and grade level; Communicating. Communicate with families about school programs and student progress and create two-way communication channels between school and home; Volunteering. Improve recruitment, training, activities, and schedules to involve families as volunteers and as audiences at the school or in other locations that enable educators to work with volunteers who support students and the school; Learning at Home. Involve families with their children in academic learning at home, including homework, goal setting, and other curriculum-related activities; Decision-Making. Include 
families as participants in school decisions, governance, and advocacy activities through school councils or improvement teams, committees, and parent organizations; and Collaborating with the Community. Coordinate resources and services for families, students, and the school with community groups, including businesses, agencies, cultural and civic organizations, and colleges or universities. Enable all to contribute service to the community.

Hamunyela (2008) concurs that "for an education system to be in tune with change it needs to be flexible, adaptable, and responsive to constantly changing circumstances and needs. Furthermore, he notes that the concept of cultural capital gives us significant insight in understanding the role schools can play in fostering parental involvement; influences parental participation in education; and helps us understand the power relations that occur within a school" (p.18).

Cultural factors have great impact on effective parental involvement. Therefore, understanding the culture of a specific group of people to be studied should be seriously taken into consideration for better understanding of parental involvement in a particular context.

However, it is also important for schools to recognize the existence of cultural differences in parent involvement. The attitudes, practices and values at home influence how parents involve themselves in school which results to the achievement gap of their children. Applying the concepts of social and cultural capital to the home-school mesosystem may promote a greater understanding of the gap and eventually how schools can address it.

Consequently, Figure 1 below is the representation of the School-facilitated Parental Involvement (SPIn), a framework which the researcher opt to develop. In this framework, the child who is the most important asset of the society is placed at the center of the paradigm to represent that he is the reason and at the same time one of the beneficiaries of the parental involvement framework. Surrounding the child is the two primary contexts in his life - home and school. The home where parent-child interactions happen, and the complex roles, meanings, and consequences associated with parenting, are embedded in and shaped by broader contexts such as extended kin networks, neighborhoods, socioeconomic class, and culture (Alampay \& Jocson, 2012). The school where the process of teaching and learning occurs and the rapport, camaraderie and assistance of parents and teachers, are formed. Relationship between the home and school are in Brofenbrenner's Bio-Ecological system which proposes that the sociocultural environment represents blueprints or prescriptions that influence and support the particular practices of parents as they interact with their children, and in turn children's responses to and behaviors towards their parents.

To bridge the connection of home and school, Epstein typology of parental involvement develops aspects in which the current study is investigating. These includes Communicating (design effective forms of school-to-home and home-to-school communications about school programs and children's progress), Volunteering (recruit and organize parent help and support), 
and Learning at home (provide information and ideas to families about how to help students at home with homework and other curriculum-related activities, decisions, and planning).

The existing literatures and stakeholders' viewpoints on the three aspects stated which are of equal value and revolves around the child will be used and highlighted in developing a School-facilitated Parenting Involvement (SPIn) Framework.

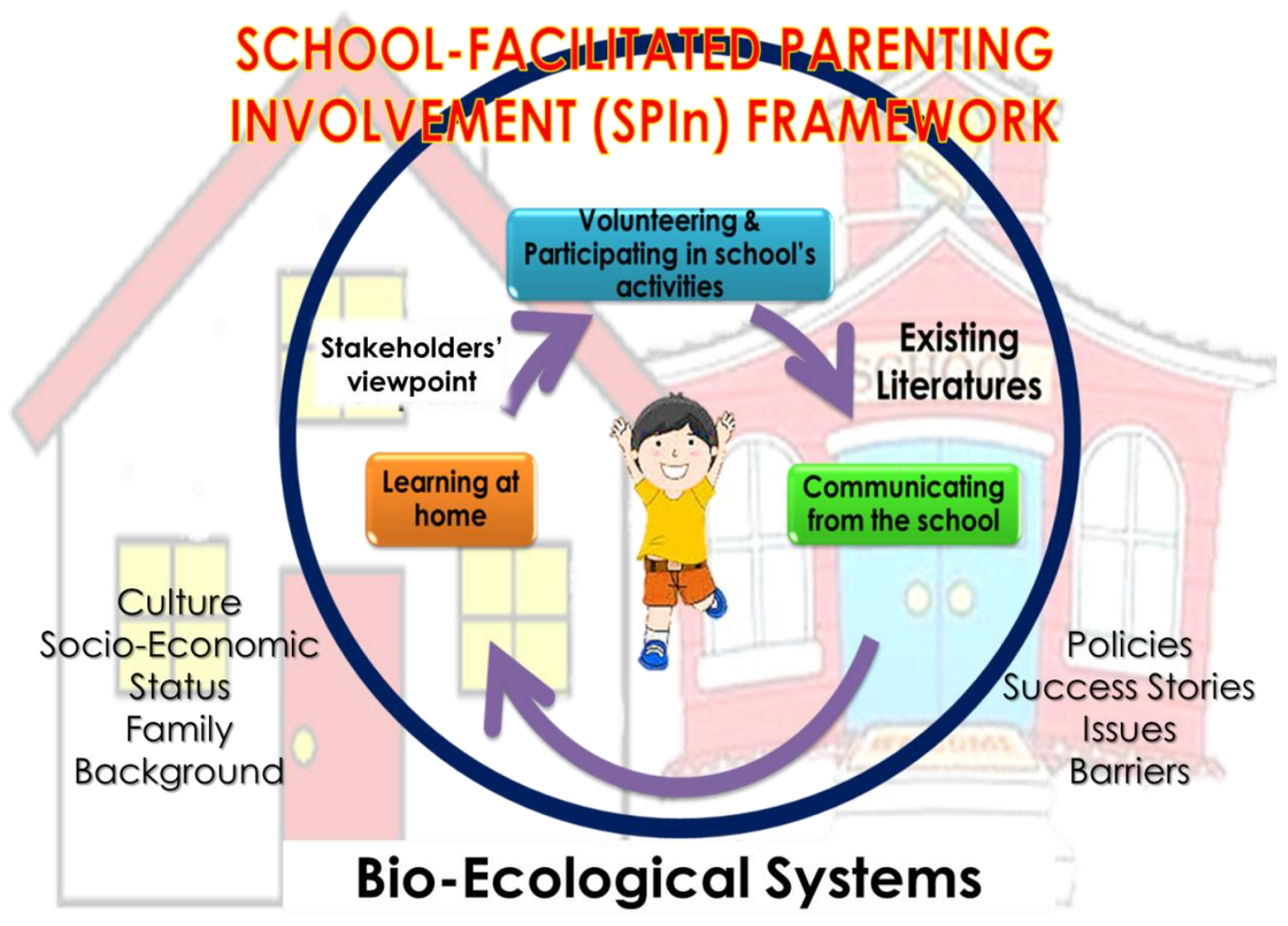

Figure 1: SPin Framework

\section{CONCLUSION}

Parent involvement placed a vital role in the education of children as well as the contribution it gives to the society. Although, there are programs and current practice on parental involvement in the Philippines, national policies and framework are not in placed to support Early Childhood Education. Statistics shows the low level of reading competence of children, studies reveal the gap in understanding PI in parents' perspective, and the Philippine EFA goals recommends to expand access of parental involvement programs in every barangays.

Literatures on parental involvement are primarily on American and western literature which are of great benefit in this area. However, it yields effects which need to be contextualized. Although different researchers state its importance and positive effects, there are still some studies that noted the barriers in promoting and doing it. Some of the studies did not consider parents' perspectives, while some have language and cultural limitations in data gathering. There are miscommunications between the schools and parents and shows the different views of each side. This gap brings a meaningful component in the development of a framework that 
will improve the relationship between parents and schools, and educational outcomes of children.

Thus, programs and activities should not just focus on the established models, but also in cultural factors that influences the holistic development of a child. Education alone cannot completely meet the needs of the changing society and the school alone cannot fulfill completely what is needed and relevant for the education. For the sake of a holistic education, parents need to play a supportive role in education and Philippine government must take into account the enactment of a council or policy for family affairs.

\section{REFERENCES}

Alampay, L. (n.d.) Parenting in the Philippines. Ateneo De Manila University (Research).

Arriero, M. L. (2006). Beginning Learning in the Home and School Readiness. University of the Philippines (Dissertation).

Blair, S. L. (2014). Parental involvement and children's educational performance: A comparison of Filipino and U.S. parents. Journal of Comparative Family Studies, 45(3), 351-36. Retrieved from http://www.jstor.org/stable/24339542

Brofenbrenner, U. (1994). Ecological Models of Human Development. International Encyclopedia of Education,Vol. 3, $2^{\text {nd }}$ Ed. Oxford: Elsevier.

Epstein, J. L. (1994). Theory to Practice: School and Family Partnerships Lead to School Improvement and Student Success. Boulder, CO: Westview Press.

Evangelista, A. D. (2008). Academic Involvement of Parents and their Children's Scholastic Performance. Trinity University of Asia (Thesis).

Goodall, J., \& Vorhaus, J. (2010). Review of Best Practice in Parental Engagement. Department for Children, Schools and Families (DCSF) which has now been replaced by the Department for Education (DFE), United Kingdom.

Hamunyela, M. (2008). A Critical Analysis of Parental Involvement in the Education of Learners in Rural Namibia. University of Pretoria (Dissertation).

Ho, E. S. (2009). Educational Leadership for Parental Involvement in an Asian Context: Insights from Bourdieu's Theory of Practice. The School Community Journal. Vol.19, No.2.

Luz, J. M. (2007). A Nation of Non-readers. Literature and Literacy Report. Retrieved from http:/pcij.org/stories/a-nation-of-nonreaders/

Monteflor et al. (2006). Parent motivation strategies and the performance of preschoolers in a rural Philippine municipality. Early Childhood Education Journal, 33(5). DOI 10.107/s10643-005-0035-1

Nierva, M. (2009). Relationship between Parental Involvement and Family Status Variables of Grade One Parents of Siena College Quezon City SY 2006-2007: Implication for the School Shared Responsibility of the Home and the School. Ateneo de Manila University (Thesis).

Nihat Şad, S., Gürbüztürk, O. (2013). Primary School Students' Parents' Level of Involvement into their Children's Education. Educational Sciences: Theory \& Practice, 13(2) Educational Consultancy and Research Center. Retrieved from www.edam.com.tr/estp

Ochoa, D., \& Torre, B. (n.d.). Parenting in the Philippines: A Review of the Research Literature from 2004 to 2014. PETA Arts Zone Project Terre de Hommes Germany.

Peters, M. (2012). Parental Involvement: How Much is Enough and What Can Schools Do to Encourage It? William Paterson University of New Jersey (Master Thesis). 
Pineda, K. (2008). Comparison of the Parents' and School Personnel's Perceptions on the Existing Home-School Collaboration Program of Woodrose School, SY 2006-2007, Implications for the Program. Ateneo de Manila (Thesis).

Sapungan, G., \& Sapungan, R. (2014). Parental involvement in child's education: importance, barriers and benefits. Asian Journal of Management Sciences \& Education, 3(2).

Selangan. (2015). The Reading Profile of Children in the Philippines. Literacy and World Languages Article. Retrieved from http://www.edutopia.org/discussion/reading-profile-children-philippines 